\title{
Penerapan Lean Manufacturing Untuk Meminimasi Waste Delay Pada Workstation Curing di PT Bridgestone Tire Indonesia
}

\author{
Yulinda Uswatun Kasanah ${ }^{(1)}$, Pratya Poeri Suryadhini ${ }^{(2)}$, Murni Dwi Astuti ${ }^{(3)}$ \\ ${ }^{(1)}$ Jurusan Teknik Industri, Fakultas Rekayasa Industri, Universitas Telkom \\ Email : yulinda.yuke12@gmail.com ${ }^{(1)}$
}

\begin{abstract}
Abstrak
Lean Manufacturing merupakan metode yang digunakan untuk meningkatkkan produktivitas dan pengurangan biaya dengan cara meminimasi pemborosan dalam proses produksi. Penelitian ini menjelaskan penggunaan Lean Manufacturing dengan tool Single Minutes Exchange Of Dies (SMED) pada lantai produksi PSR di PT XYZ, yang bergerak dalam bidang Automotive Manufacture berupa pembuatan ban mobil. Tahap penelitian diawali dengan melakukan analisis waste dengan Mapping tools dilanjutkan dengan mengidentifikasi penyebab pemborosan pada workstation curing. Tahap Selanjutnya adalah menganalisis tahapan proses setup mesin curing yang terdiri dari setup benda kerja, setup mold, setup curing, dan setup finishing. Berdasarkan hasil pengamatan, jumlah waktu setup keadaan awal adalah 194,05 menit. Perbaikan yang dilakukan adalah dengan mengkonversi aktivitas internal setup menjadi eksternal setup, pengurangan aktivitas perpindahan operator, eliminasi adjusment, dan menerapkan operasi paralel yaitu dengan menggunakan 2 operator. Sehingga total waktu setup yang dapat direduksi adalah 127,41 menit.
\end{abstract}

Kata Kunci: Lean manufacture, SMED, Waktu setup, Workstation curing

\begin{abstract}
Lean Manufacturing is a method used to increased productivity and costs reduction by minimizing waste in the production process. This study describe the use of lean manufacturing with Single Minutes Exchange Of Dies tools on the PSR's production floor in PT XYZ, which is engaged in automotive manufacture form making of car tires. Research stage begins by analyzing waste using mapping tool and identification causes of waste in workstation curing. The next stage is analyzing every step of machine setup that occurs are workpiece setup, mold setup, curing setup, and finishing setup. Based on observations, the amount of the initial state setup time is 194,05 minutes. The improvement begin by convert internal activities setup into external setup, reduction of operator displacement activity, elimination of adjusment, and apply a parallel operation by using two operators. So the total setup time can be reduced is equal to 127,41 minutes.
\end{abstract}

Keyword : Lean manufacture, SMED, Setup time, Workstation curing. 


\section{Pendahuluan}

PT. Bridgestone Tire Indonesia merupakan salah satu perusahaan manufacturing yang bergerak dalam bidang otomotif yang memproduksi ban luar mobil, ban dalam mobil, dan lidah ban mobil. PT. Bridgestone Tire Indonesia merupakan salah satu produsen ban terbesar di Indonesia yang memiliki beberapa family produk seperti Passenger Tires, Commercial Tires, dan Industrial Tires. Departemen Passanger Radial (PSR) merupakan departemen yang memproduksi ban mobil untuk kendaraan pribadi atau mobil penumpang, seperti Ecopia, Potenza, dan Techno.

Dalam memproduksi produk-produk tersebut, terdapat beberapa kendala yang menyebabkan perusahaan tidak dapat menyelesaikan order tepat waktu sesuai dengan perencanaan yang telah ditetapkan. Maka dilakukan pengamatan dan wawancara yang dilakukan untuk mengetahui faktorfaktor penyebab terjadinya keterlambatan dalam penyelesaian order. Hasil pengamatan menunjukkan bahwa faktor penyebab keterlambatan adalah adanya delay pada workstation curing yang disebabkan oleh lamanya waktu setup mesin curing [1],[2].

Proses setup merupakan proses pengaturan mesin ketika terjadi perubahan jenis produk (changeover). Tahapan setup dalam memproduksi Passanger Tires yaitu setup benda kerja, setup mold, setup curing, dan setup finishing. Setup benda kerja merupakan setup yang dilakukan pada tire setengah matang (green tire) seperti penyemprotan silicon pada bagian dalam dan luar green tire, setup mold merupakan pengaturan posisi cetakan tire (mold tire) pada mesin tatakan mold yang disesuaikan dengan size tire, setup finishing merupakan finishing untuk setup mold seperti pembersihan mold dan pemeriksaan posisi mold. Berdasarkan faktor yang mempengaruhi masalah keterlambatan dalam penyelesaian order komponen Isolating Cock, waktu setup dianggap mempengaruhi keterlambatan dalam penyelesaian order.

Tabel 1 jumlah order yang belum terpenuhi pada shift 1

\begin{tabular}{|c|c|c|c|c|c|c|}
\hline Size Tire & $\begin{array}{c}\text { Kapasitas 1 } \\
\text { mesin (unit } \\
\text { /shift) }\end{array}$ & $\begin{array}{c}\text { Jumlah } \\
\text { order 1 } \\
\text { mesin /shift } \\
\text { (unit) }\end{array}$ & $\begin{array}{c}\text { Set up } \\
\text { mesin } \\
\text { (menit) }\end{array}$ & $\begin{array}{c}\text { Waktu } \\
\text { proses } \\
\text { (menit) }\end{array}$ & $\begin{array}{c}\text { Jumlah } \\
\text { produksi } \\
\text { (unit) }\end{array}$ & $\begin{array}{c}\text { Selisih } \\
\text { order dan } \\
\text { jumlah } \\
\text { produksi }\end{array}$ \\
\hline $\begin{array}{c}\text { Ecopia } \\
\text { MPV-1 }\end{array}$ & 30 & 30 & 0 & 13,2 & 30 & 0 \\
\hline $\begin{array}{c}\text { Potenza } \\
\text { REO50 }\end{array}$ & 30 & 30 & 121,0 & 15,0 & 12 & $-18,067$ \\
\hline Total & $\mathbf{6 0}$ & $\mathbf{6 0}$ & $\mathbf{1 2 1 , 0}$ & $\mathbf{2 8 , 2}$ & $\mathbf{4 1 , 9}$ & $\mathbf{- 1 8 , 1}$ \\
\hline $\begin{array}{c}\text { Ecopia } \\
\text { MPV-1 }\end{array}$ & 30 & 30 & 0 & 13,2 & 30 & 0 \\
\hline
\end{tabular}

(Sumber: Olah Data)

Tabel 1 menunjukkan bahwa jumlah order yang tidak terpenuhi pada shift 1 pada 1 mesin adalah sebesar 18 unit. Terlihat pada produk Ecopia ketika tidak ada changeover maka order dapat dipenuhi. Ketika terjadi changeover seperti dari produk Ecopia ke Potenza maka waktu produksi dalam 1 shift berkurang sejumlah besarnya waktu setup.

Jika waktu setup ini bisa diminimasi maka akan diperoleh jumlah produksi mesin perunit yang lebih besar, karena meminimasi waktu setup sama dengan mengurangi waktu yang terbuang untuk melakukan setup time [3],[4]. Melihat kondisi tersebut, maka diperlukan adanya perbaikan pada Workstation Curing dengan cara mengeliminasi waste delay sehingga order dapat terpenuhi. Jika waktu setup dapat diminimasi, maka akan semakin banyak produk yang dapat diproduksi oleh perusahaan [5],[6].

Melihat kondisi tersebut, maka diperlukan adanya perbaikan pada Workstation Curing dengan cara mengeliminasi waste delay sehingga order dapat terpenuhi . Perbaikan dalam meminimasi waste delay adalah dengan mereduksi waktu setup dengan metode Single-Minute Exchange of Die atau lebih dikenal dengan istilah SMED [6],[7]. 


\section{Metode Penelitian}

Variabel pertama berupa data yang didapatkan dengan pengamatan langsung kelapangan untuk mengukur waktu dengan menggunakan Stopwatch Time Study dan mengumpulkan data lain seperti urutan proses produksi dan layout lantai produksi untuk mengetahui aliran material produksi . Setelah data terkumpul maka variabel selanjutnya akan digunakan sebagai dasar pemetaaan keadaan proses produksi saat ini dengan menggunakan Value Stream Mapping (VSM current state) [8],[9],[10],[6]. Untuk memetakan keadaan proses yang terjadi serta mengidentifikasi pemborosan dan lead time maka dilakukan pemetaan dengan menggunakan salah satu Detailed mapping. Detailed mapping ini diperlukan untuk menggambarkan proses produksi yang lebih detail sehingga memudahkan dalam mengidentifikasi pemborosan yang terjadi.

Variabel selanjutnya berupa data pengamatan dan observasi untuk mengidentifikasi pemborosan yang terjadi pada lantai produksi dengan menganalisis detailed mapping terpilih untuk menentukan pemborosan terbesar. Setelah pemborosan pada lantai produksi terdefinisi maka langkah selanjutnya adalah mencari akar masalah pemborosan dengan menggunakan fishbone chart dan 5 whys. Setelah akar masalah ditemukan maka tahap selanjutnya adalah melakukan perbaikan dengan menerapkan salah satu tools Lean Manufacturing yang sesuai dengan masalah yang teidentifikasi. Strategi perbaikan yang dibuat dengan menggunakan pendekatan Lean Manufacturing menjadi sesuai dengan perbaikan yang dilakukan. Gambar III.1 pada halaman 35 menunjukan model konseptual dalam penelitian ini [11],[12],[13].

Tahap ini dimulai dari tahap pengumpulan data. Pengumpulan data dilakukan untuk memperoleh data-data yang diperlukan untuk pengolahan data sesuai dengan masalah yang dihadapi. Pengukuran langsung dilakukan dengan menggunakan stopwatch pada beberapa data waktu proses produksi. Pengumpulan data yang lain yaitu data aliran proses dan peta lantai kerja produksi. Setelah data waktu diperoleh maka dilakukan uji kecukupan dan kenormalan data.

Membuat Big Picture Mapping dengan Value Stream Mapping current state. Berdasarkan data waktu produksi yang telah diberikan maka dilakukan pembuatan big picture mapping dengan menggunakan VSM current state untuk melihat aliran proses yang sebenarnya, cycle time setiap proses produksi, kebutuhan man power dalam proses produksi, dan proses ini menghasilkan data lead time yang dapat digunakan untuk mengidentifikasi pemborosan.

Mengidentifikasi waste yang terjadi dan mendefinisikannya kedalan 7 waste [5],[14],[15],[16]. Pencarian jenis-jenis waste pada proses produksi dilakukan setelah pengamatan langsung. Pencarian jenis waste disesuaikan dengan studi literatur dan studi menggunakan Waste Assesment Model (WAM) yang telah dilakukan pada awal observasi penelitian ini dilakukan. Kemudian pembobotan waste yang telah didapat akan dijadikan sebagai output dalam pemilihan mapping tools yang akan digunakan. Setelah mapping tools terpilih maka bisa dilakukan identifikasi waste yang akan menjadi dasar untuk melakukan perbaikan [17].

Mengidentifikasi akar masalah pemborosan. Setelah pemborosan terdefinisi maka langkah selanjutnya adalah menentukan akar masalah dengan menggunakan fishbone chart [18],[19],[20]. Jika fishbone chart belum menjawab akar masalah dari pemborosan terpilih maka dilakukan identifikasi 5 whys.Melakukan perbaikan setelah akar masalah diketahui maka rancangan big picture mapping dengan value stream mapping (VSM) future state dapat dirancang dan dapat dilakukan perbaikan dengan menggunakan metode SMED untuk meminimasi waktu setup mesin..Perbaikan yang dilakukan tidak sampai pada implementasi.

Tahap Analisis dan Kesimpulan. Tahap ini merupakan tahap terakhir dalam penelitian ini. Tahap ini memaparkan analisa perbaikan yang dilakukan pada proses produksi, serta berisi kesimpulan dan saran penulis terhadap penelitian yang dilakukan. Kesimpulan diambil berdasarkan keseluruhan rancangan perbaikan yang sudah dianalisa, saran merupakan rekomendasi pihak perusahaan dan peneliti selanjutnya. 


\section{Hasil dan Pembahasan}

\section{Big Picture Mapping}

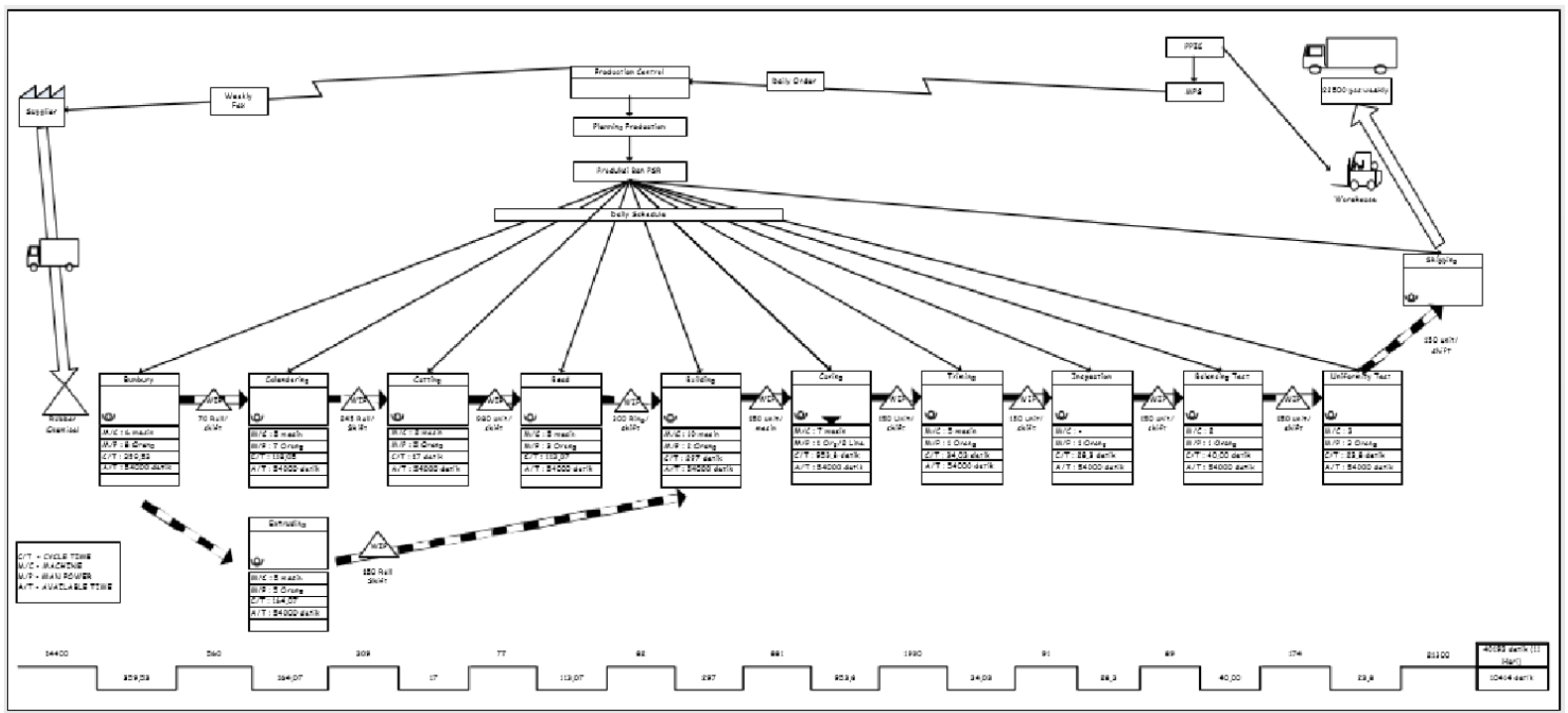

Gambar 1 Value Stream Mapping proses produksi PSR

Gambar 1 memperlihatkan value stream mapping pada lantai produksi pembuatan ban jenis radial (PSR). Dalam VSM ini diperlihatkan rata-rata jumlah produksi yang dapat dihasilkan untuk setiap workstation dan available time dari setiap workstation.

Mapping tools

Tabel 2 process activity mapping lantai produksi PSR

\begin{tabular}{|c|c|c|c|c|c|c|c|c|c|c|c|}
\hline \multirow{2}{*}{ No. } & \multirow{2}{*}{$\begin{array}{l}\text { Deskripsi } \\
\text { Aktivitas }\end{array}$} & \multirow{2}{*}{$\begin{array}{c}\text { Mesin/Alat } \\
\text { Bantu }\end{array}$} & \multirow{2}{*}{$\begin{array}{c}\text { Jarak } \\
(\mathrm{m})\end{array}$} & \multirow{2}{*}{$\begin{array}{l}\text { Waktu } \\
\text { (detik) }\end{array}$} & \multirow{2}{*}{$\begin{array}{l}\text { Jumlah } \\
\text { (Man } \\
\text { power) }\end{array}$} & \multicolumn{5}{|c|}{ Aliran } & \multirow{2}{*}{$\begin{array}{l}\text { NVA/VA } \\
\text { /NNVA }\end{array}$} \\
\hline & & & & & & $\mathrm{O}$ & $\mathrm{T}$ & I & $S$ & $\mathrm{D}$ & \\
\hline 1 & $\begin{array}{c}\text { Mengambil } \\
\text { raw material } \\
\text { dari } \\
\text { warehouse }\end{array}$ & & 8 & 45 & \multirow{3}{*}{2} & & & & & & NNVA \\
\hline 2 & $\begin{array}{l}\text { Menimbang } \\
\text { raw material }\end{array}$ & $\begin{array}{c}\text { Penimbang } \\
\text { material }\end{array}$ & & 39 & & & & & & & VA \\
\hline 3 & $\begin{array}{c}\text { Memasukkan } \\
\text { material } \\
\text { kedalam } \\
\text { mesin } \\
\text { bunbury }\end{array}$ & & & 15 & & & & & & & NNVA \\
\hline 4 & $\begin{array}{c}\text { Proses } \\
\text { bunbury } \\
\text { mixing }\end{array}$ & BB F270 & & 312 & & & & & & & VA \\
\hline 5 & $\begin{array}{l}\text { Menempatka } \\
\mathrm{n} \text { compund } \\
\text { kedalam } \\
\text { pendingin }\end{array}$ & Pendingin & 1 & 11 & & & & & & & NNVA \\
\hline
\end{tabular}


Tabel 2 process activity mapping lantai produksi PSR (lanjutan)

\begin{tabular}{|c|c|c|c|c|c|c|c|c|c|c|c|}
\hline \multirow{2}{*}{ No. } & \multirow{2}{*}{$\begin{array}{l}\text { Deskripsi } \\
\text { Aktivitas }\end{array}$} & \multirow{2}{*}{$\begin{array}{l}\text { Mesin/Alat } \\
\text { Bantu }\end{array}$} & \multirow{2}{*}{$\begin{array}{l}\text { Jarak } \\
(\mathrm{m})\end{array}$} & \multirow{2}{*}{$\begin{array}{l}\text { Waktu } \\
\text { (detik) }\end{array}$} & \multirow{2}{*}{$\begin{array}{l}\text { Jumlah } \\
\text { (Man } \\
\text { power) }\end{array}$} & \multicolumn{5}{|c|}{ Aliran } & \multirow{2}{*}{$\begin{array}{l}\text { NVA/VA } \\
\text { /NNVA }\end{array}$} \\
\hline & & & & & & $\mathrm{O}$ & $\mathrm{T}$ & I & $S$ & $\mathrm{D}$ & \\
\hline 6 & $\begin{array}{l}\text { Menunggu } \\
\text { pendinginan } \\
\text { compound }\end{array}$ & & & 83 & & & & & & & NVA \\
\hline 7 & $\begin{array}{l}\text { Menggulung } \\
\text { compound }\end{array}$ & BB dusting & & 9 & & & & & & & VA \\
\hline 8 & $\begin{array}{l}\text { Menempatka } \\
\mathrm{n} \text { compound } \\
\text { pada rak }\end{array}$ & Rak WIP & 2 & 11 & & & & & & & NNVA \\
\hline 9 & $\begin{array}{l}\text { Meletakkan } \\
\text { compound } \\
\text { pada } \\
\text { inventory } \\
\text { F/G Bunbury }\end{array}$ & Forclift & 3 & 35 & & & & & & & NNVA \\
\hline 10 & $\begin{array}{c}\text { Mengambil } \\
\text { cement }\end{array}$ & & 1 & 23 & & & & & & & NNAV \\
\hline 11 & $\begin{array}{l}\text { Meletakkan } \\
\text { compound } \\
\text { dan cement }\end{array}$ & & & 13 & & & & & & & VA \\
\hline 12 & $\begin{array}{l}\text { Proses tread } \\
\text { extruder }\end{array}$ & $\begin{array}{l}\text { Single } \\
\text { Tuber } 8 "\end{array}$ & & 164 & & & & & & & VA \\
\hline Total & & & 109,5 & 4659 & & & & & & & \\
\hline
\end{tabular}

(Sumber : Olah Data)

Berdasarkan PAM yang telah dibuat pada Tabel 2 maka dapat dibuatkan tabulasi ringkasan perhitungan dan prosentase PAM pada tabel 3 berikut.

Tabel 3 Ringkasan perhitungan hasil PAM

\begin{tabular}{|c|c|c|}
\hline Aktivitas & Jumlah & Waktu (detik) \\
\hline Operation & 20 & 2400 \\
\hline Transport & 26 & 923 \\
\hline Inspection & 2 & 44 \\
\hline Storage & 4 & 232 \\
\hline Delay & 10 & 1060 \\
\hline Total & 62 & 4659 \\
\hline Klasifikasi & Jumlah & waktu (detik) \\
\hline VA & 20 & 2400 \\
\hline NVA & 10 & 1060 \\
\hline NNVA & 32 & 1199 \\
\hline Total & 62 & 4659 \\
\hline \multicolumn{2}{|c|}{ Value Ratio } & 0,52 \\
\hline
\end{tabular}




\section{(Sumber : Olah Data)}

Pada tabel 3 memperlihatkan bahwa value ratio untuk proses produksi pembuatan ban PSR adalah sebesar 0,52 atau $52 \%$. Value ratio merupakan nilai perbandingan antara aktivitas yang memberikan nilai tambah dengan keseluruhan aktivitas. waste dengan waktu terbesar yaitu waste delay, dengan waktu delay sebesar 1060 detik dan waktu delay terbesar adalah pada aktivitas green tire yang menunggu untuk di curing. Selanjutnya akan diidentifikasi penyebab terjadinya delay pada mesin curing.

\section{Penerapan Metode SMED}

Usulan perbaikan proses setup dilakukan dengan menggunakan metode SMED. Langkah-langkah pemecahan masalah dengan menerapkan metode SMED adalah sebagai berikut :

Langkah Pertama : Memisahkan Internal dan Setup Eksternal

Setelah diperoleh urutan dan waktu proses setup, maka dlakukan pemisahan setup internal dan setup internal. Hal tersebut dilakukan dengan melakukan pengamatan langsung dan mengajukan pertanyaan kepada operator, jika mesin harus dimatikan untuk mengerjakan proses setup maka proses setup tersebut dimasukkan ke dalam internal setup. Jika mesin tidak harus dimatikan untuk mengerjakan proses setup maka proses setup tersebut dimasukkan ke dalam eksternal setup. Seluruh aktivitas setup merupakan setup internal atau setup yang dilakukan terjadi saat mesin tidak beroperasi.

Langkah Kedua : Mengkonversi Setup Internal Menjadi Setup Eksternal

Seluruh aktivitas setup merupakan setup internal, sehingga kegiatan setup internal dikonversi menjadi setup eksternal. Aktivitas yang dapat dikonversi ke dalam eksternal setup adalah aktivitas preheat mold (pemasanan mold), mengambil (menyiapkan) perkakas, dan setup benda kerja (green tire). Dengan melakukan konversi internal setup menjadi eksternal setup dapat mereduksi waktu setup. Waktu setup yang dapat direduksi yaitu sebesar 63,70 menit

Tabel 4 Konversi setup internal menjadi setup eksternal

\begin{tabular}{|l|l|l|l|l|}
\hline $\begin{array}{l}\text { Jenis } \\
\text { Setup }\end{array}$ & Kegiatan & Intern & Ekstern & $\begin{array}{l}\text { Waktu } \\
\text { (Menit) }\end{array}$ \\
\hline \multirow{4}{*}{$\begin{array}{l}\text { Setup } \\
\text { Lepas }\end{array}$} & Mematikan mesin curing (mesin stop) & $\sqrt{ }$ & & 0,56 \\
\hline & Mengambil tag (untuk kode SNE) & & $\sqrt{ }$ & 1,41 \\
\hline & Memasang tag kode SNE & $\sqrt{ }$ & & 0,55 \\
\hline & Mengambil kotak perkakas & & $\sqrt{ }$ & 0,71 \\
\hline & Mencari obeng pembuka baut bladder & $\sqrt{ }$ & & 0,23 \\
\hline & Mengambil obeng pembuka baut bladder & $\sqrt{ }$ & & 0,23 \\
\hline & Melepas baut bladder kanan & $\sqrt{ }$ & & 1,72 \\
\hline & Membongkar bladder kanan & $\sqrt{ }$ & & 1,24 \\
\hline
\end{tabular}




\begin{tabular}{|l|l|l|l|} 
Melepas baut bladder kiri & $\sqrt{ }$ & 1,28 \\
\cline { 2 - 4 } Membongkar bladder kiri & $\sqrt{ }$ & 1,35 \\
\cline { 2 - 4 } & $\begin{array}{l}\text { Meletakkan bladder kanan dan kiri pada } \\
\text { tempat penyimpanan }\end{array}$ & $\sqrt{ }$ & 2,68 \\
\hline
\end{tabular}

(Sumber : Olah Data)

Langkah Ketiga : Streamlining (Penyederhanaan) Terhadap Seluruh Aktivitas Setup Penyederhanaan dilakukan terhadap seluruh aktivitas setup, dilakukan dengan cara :

Pengurangan aktivitas perpindahan operator. Perpindahan operator untuk mencari dan mengambil komponen maupun material merupakan salah satu pemborosan. Spaghetti diagram dapat digunakan untuk merekam perpindahan operator ketika setup. Diagram ini dapat digunakan untuk menggambarkan kompleksitas dalam setup. Gambar menunjukkan spaghetti diagram perpindahan operator pada proses setup mesin curing.

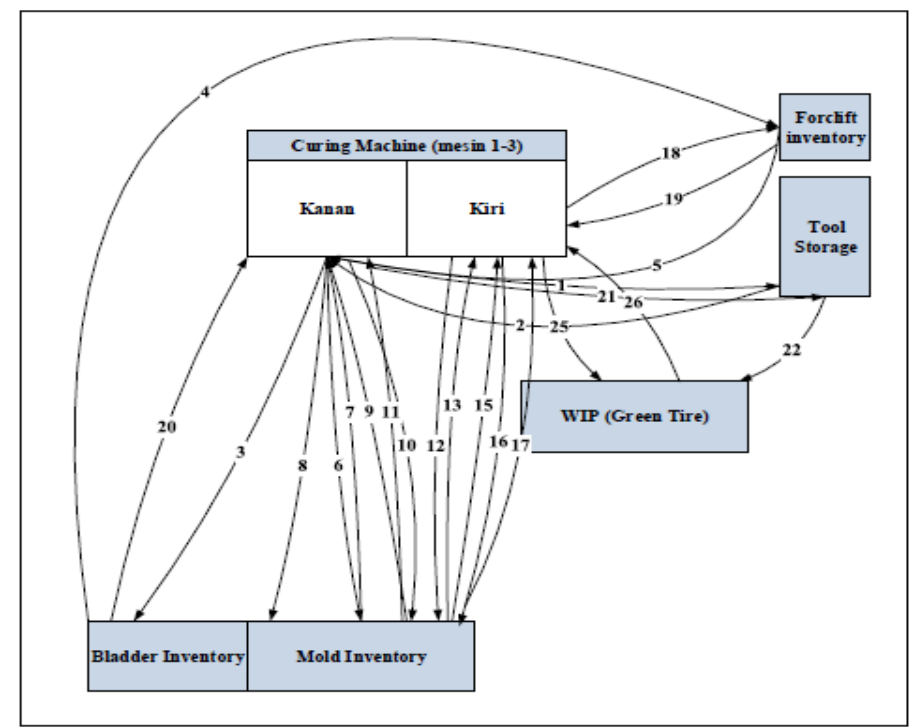

Gambar 2 spaghetti diagram perpindahan operator

Aktivitas setup yang tereduksi karena adanya pemindahan tool storage yang terpasang dekat dengan mesin sehingga operator tidak perlu melakukan perpindahan untuk mengambil kotak perkakas, tag kode SNE, dan alat pembersih mold di tool storage. Setup eksternal tereduksi adalah sebesar 3,06 menit. Sehingga waktu setup eksternal menjadi 61,04 menit.

\section{Eliminasi Adjusment}

Salah satu waktu setup yang cukup besar adalah waktu setup untuk penyetelan dan penyesuaian parameter pada mesin curing. Aktivitas yang dapat distandarkan adalah eliminasi adjusment pemasangan mold. Adjusment pada pemasangan mold bawah yaitu berupa penyesuaian mold bawah dengan tatakan mesin curing. Ketika mold telah diangkut menggunakan forclift dan diletakkan pada 
mesin curing maka harus ada penyesuaian berupa centering mold dan penyesuaian lubang baut mold dengan lubang baut tatakan mesin. Jumlah baut dalam satu mold bawah yaitu 6 buah baut. Sehingga untuk meghilangkan penyesuaian trial and error pemasangan mold bawah maka harus dibuat sign yang dapat memudahkan operator untuk melakukan centering mold.

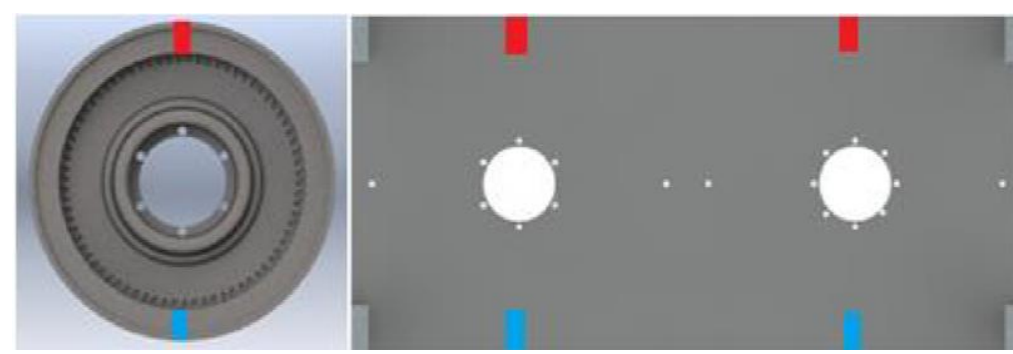

Gambar 3 penandaan (sign) warna pada mold dan tatakan

Selain itu, masih terdapat percobaan bladder untuk memastikan bahwa bladder dapat mengembang dengan sempurna (trial and error). Penyesuian pada bladder harus dilakukan dalam keadaan mesin menyala atau eksternal setup sehingga penyesuaian bladder tidak dapat dilakukan ketika mesin mati. Berdasarkan hasil penyederhanaan ke-2 diperoleh reduksi waktu setup yang telah diakumulasikan dengan proses sebelumnya yaitu sebesar 4,32 menit. Sehingga waktu setup internal menjad 126,79 menit.

Menerapkan operasi paralel

Operasi paralel dapat dilakukan dengan melibatkan lebih dari satu operator untuk melakukkan setup mesin. pembagian kerja dilakukan dengan 2 cara yaitu membagi tugas dalam dua bagian yaitu, operator 1 menjalankan setup mold dan setup curing (melakukan pindah tempat hanya dari mold kanan ke mold kiri, atau sebaliknya). Sedangkan operator 2 (sebagai asisten operator) menjalankan perpindahan/transportasi pengambilan, penyimpanan, dan pembersihan peralatan seperti mold dan bladder, serta melakukan setup benda kerja. Operasi setup paralel ini lebih ditujukan untuk meminimasi waktu setup internal, membagi tugas dalam dua bagian yaitu, operator 1 menjalankan setup mold kanan dan menjalankan mesin, sedangkan operator 2 melakukan setup mold kiri dan setup benda kerja.

\section{Kesimpulan}

Penerapan metode SMED dalam kegiatan setup yang dilakukan pada workstation curing dapat mereduksi waktu setup internal sebesar 127,47 menit dan waktu setup eksternal sebesar 3,06 menit. Aktivitas setup dapat direduksi dengan beberapa cara yaitu mengkonversi aktivitas yang masih tergolong aktivitas setup internal seperti setup green tire, preheat mold, dan aktivitas mengambil perkakas yang dapat direduksi sebesar 63,70 menit. Selain itu reduksi aktivitas setup dapat dilakukan dengan melakukan pergantian peralatan secara cepat dan melakukan setup paralel dengan menambah asisten operator yang dapat mereduksi waktu setup masing - masing sebesar 4,32 menit dan 60,15 menit.

Saran yang diberikan adalah perhitungan aspek finansial sebaiknya dimasukkan dalam bab analisis sebagai evaluasi rekomendasi dan manfaat perbaikan. Dapat dilakukan penelitian lebih mendalam dalam penerapan lean manufacturing pada proses produksi jilbab anak terhadap waste lain yang terdeteksi. 


\section{Daftar Pustaka}

[1] J. Wakiru, L. Pintelon, P. N. Muchiri, and P. Chemweno, "Maintenance Optimization: Application of Remanufacturing and Repair Strategies," Procedia CIRP, vol. 69, no. May, pp. 899-904, 2018.

[2] M. M. Firmansyah, A. Susanty, and D. Puspitasari, "Analisis Overall Equipment Effectiveness dan Six Big Losses pada Mesin Pencelupan Benang (Studi Kasus PT. Pismatex Textile Industry)," Ind. Eng. Online J., vol. 4, no. 4, 2015.

[3] P. Shetty and B. \{Prakash Rao\}, "Importance of lean concepts and its need in construction projects," Int. J. Recent Technol. Eng., vol. 8, pp. 2534-2541, 2019.

[4] A. K. Möldner, J. A. Garza-Reyes, and V. Kumar, "Exploring lean manufacturing practices' influence on process innovation performance," J. Bus. Res., vol. 106, no. May 2018, pp. 233 $249,2020$.

[5] P. Arunagiri and A. Gnanavelbabu, "Identification of major lean production waste in automobile industries using weighted average method," Procedia Eng., vol. 97, pp. 2167-2175, 2014.

[6] A. Azizi and T. a/p Manoharan, "Designing a Future Value Stream Mapping to Reduce Lead Time Using SMED-A Case Study," Procedia Manuf., vol. 2, no. February, pp. 153-158, 2015.

[7] K. Salonitis and C. Tsinopoulos, "Drivers and Barriers of Lean Implementation in the Greek Manufacturing Sector," Procedia CIRP, vol. 57, pp. 189-194, 2016.

[8] T. Widodo and I. Ferdiansyah, "Implementasi Lean Dengan Menggunakan Value Stream Mapping Untuk Mempercepat Lead Time Proses Outbound Di Pt . X,” vol. 2, no. 2, pp. 85-91, 2017.

[9] W. Adrianto and M. Kholil, "Analisis Penerapan Lean Production Process untuk Mengurangi Lead Time Process Perawatan Engine (Studi Kasus PT.GMF AEROASIA)," J. Optimasi Sist. Ind., vol. 14, no. 2, p. 299, 2016.

[10] R. Prasetyo Lukodono and R. Soenoko, "Analisis Penerapan Metode RCM Dan MVSM Untuk Meningkatkan Keandalan Pada Sistem Maintenance (Studi Kasus PG. X) Mahasiswa Jurusan Teknik Mesin Program Magister Fakultas Teknik UB," J. Rekayasa Mesin, 2013.

[11] M. K. Wyrwicka and B. Mrugalska, "Mirages of Lean Manufacturing in Practice," Procedia Eng., vol. 182, pp. 780-785, 2017.

[12] E. A. P. H. Putra and Z. F. Ikatrianasari, "Penerapan Lean Manufacturing melalui Metode Gemba Kaizen dengan Pendekatan Siklus PDCA untuk Peningkatan Produktivitas di PT. XYZ, Bekasi,” Magister Tek. Ind., vol. ISBN : 978, pp. 978-979, 2012.

[13] D. T. Matt and E. Rauch, "Implementation of lean production in small sized enterprises," Procedia CIRP, vol. 12, pp. 420-425, 2013.

[14] R. N. Yusfi and T. P. Damanhur, "Study Of Solid Waste Characteristics And Recycle Potential In Cikapundung Riverbanks," J. Tek. Lingkung., vol. 18, no. 2, pp. 155-166, 2012.

[15] M. Rossini, F. Costa, A. P. Staudacher, and G. Tortorella, "Industry 4.0 and lean production: An empirical study," IFAC-PapersOnLine, vol. 52, no. 13, pp. 42-47, 2019.

[16] R. Sundar, A. N. Balaji, and R. M. Satheesh Kumar, "A review on lean manufacturing implementation techniques," Procedia Eng., vol. 97, pp. 1875-1885, 2014.

[17] D. Triagus Setiyawan, S. Soeparman, and R. Soenoko, "Minimasi Waste Untuk Perbaikan Proses Produksi Kantong Kemasan Dengan Pendekatan Lean Manufacturing," J. Eng. Manag. 
Industial Syst., vol. 1, no. 1, pp. 8-13, 2013.

[18] R. Hutagaol, "Analysis of the Implementation of Nursing Professional Values in Referral Hospitals Jakarta: Fishbone Analysis,” Int. J. Nurs. Heal. Serv., vol. 2, no. 1, pp. 108-116, 2019.

[19] Nasir, "FISHBONE STRATEGY IN TEACHING ENGLISH IN INDONESIA: A TOOL," $J$. Chem. Inf. Model., vol. 53, no. 9, pp. 1689-1699, 2019.

[20] H. P. Bloch, "Root Cause Failure Analysis," in Petrochemical Machinery Insights, 2017. 